\title{
Experiência Institucional
}

RESUMo

O objetivo do artigo é relatar uma experiência de acompanhamento terapêutico escolar com uma criança autista, realizado durante três anos e meio em uma escola particular de Salvador. Os dados foram registrados em um diário de campo e analisados a partir da abordagem psicanalitica. Observaram-se avanços significativos relacionados à emergência do sujeito, como mudanças na fala, no reconbecimento de si, do corpo e no brincar simbólico. A prática mostra-se como um recurso importante para a inclusão e para o desenvolvimento de crianças autistas.

Descritores: acompanhamento terapêutico; inclusão escolar; autismo.

\section{ACOMPANHAMENTO TERAPÊUTICO ESCOLAR E AUTISMO: CAMINHOS PARA A EMERGÊNCIA DO SUJEITO}

\author{
Verônica Gomes Nascimento \\ Alan Souza Pereira Silva \\ Maria Virgínia Machado Dazzani
}

DOl: http//dx.doi.org/10.11606/issn. 1981-1624.v20i3p520-534

()

acompanhamento terapêutico escolar (ATE) é uma prática que tem sido utilizada no processo de inclusão escolar de crianças com necessidades educativas especiais (Pegorelli, 2011). Fráguas e Berlinck (2001) descrevem que o trabalho do acompanhante consiste em estar com a criança dentro e fora da sala de aula, sempre buscando integrá-la ao grupo e levá-la a um envolvimento com as atividades propostas pelo professor, observando e respeitando seus limites e suas potencialidades. Para Assali, Rizzo, Abbamonte e Amâncio

- Mestranda em Psicologia do Desenvolvimento pela Universidade Federal da Bahia (UFBA), Salvador, BA, Brasil.

- Mestrando em Psicologia do Desenvolvimento pela Universidade Federal da Bahia (UFBA), Salvador, BA, Brasil.

- a Professora do Instituto de Psicologia da Universidade Federal da Bahia (UFBA), Salvador, BA, Brasil. 
(1999), o acompanhante precisa trabalhar descobrindo o universo da criança e, com isso, construir condições para que ela possa frequentar a escola e aproveitar esse momento de modo particular. O papel do acompanhante, a rigor, é auxiliar as crianças com dificuldades severas, como o autismo, atuando como mediador e facilitador do processo de inclusão (Barros \& Brandão, 2011).

É importante destacar que existem diferentes formas de realizar tal atuação, considerando que não é específica de uma única área ou abordagem teórica. Profissionais de diversas áreas, como Psicologia, Educação, Fisioterapia e Educação Física têm atuado como acompanhantes, com perspectivas teóricas e metodológicas diversificadas. Isso significa que os objetivos e as intervenções podem assumir características bem diferentes, de acordo com o profissional que atua e com a sua respectiva abordagem teórica.

\section{O acompanhamento terapêutico escolar: caracterizações a partir da psicanálise}

Serão utilizados alguns conceitos da psicanálise para discutir as características da atuação do acompanhamento terapêutico escolar, considerando os efeitos terapêuticos produzidos pelo processo inclusivo. Kupfer (1997) aponta que a intenção com esse processo é aproveitar o potencial terapêutico que está presente em todo ato educativo voltado para o sujeito. Kupfer e Petri (2000) afirmam que "a inclusão produz ainda efeitos terapêuticos para a criança cuja subjetivação encontra obstáculos que um velho pátio de escola ainda pode ajudar a transpor" (p. 115). Sendo assim, o trabalho do acompanhante terapêutico escolar se dá sobre uma criança com dificuldades de diversas ordens, principalmente simbólicas, e se orienta para a emergência, retomada e fortalecimento do sujeito.

O acompanhante trabalha e intervém "entre" o pedagógico/ educativo e o terapêutico (Fráguas \& Berlinck, 2001), tecendo articulações possíveis na direção das estratégias inclusivas e no processo de constituição subjetiva. Dessa forma, podemos afirmar que o acompanhante trabalha em um lugar do "entre": entre a criança e as outras crianças, "entre" a criança e o professor, "entre" a criança e a escola e, em alguns casos, "entre" a criança e a família. Segundo Assali et al. (1999), há um investimento na possibilidade da criação 
de vínculos com as outras crianças e com a professora; e busca-se ajudar a criança a permanecer na sala o máximo de tempo possível, convidando-a incessantemente para as atividades propostas, aproveitando e significando as suas iniciativas, envolvendo-a em um contexto social e educacional. Assim, o acompanhante convoca a criança para a rotina e para a regra, atuando também sobre o ato educativo e produzindo um efeito terapêutico, pois ao submetê-la às regras escolares, supõe-se a existência de um sujeito (Assali et al., 1999), o qual pode vir a compreendê-las e sustentá-las.

Num primeiro momento, o acompanhante assume uma presença ativa (Montellano et al., 2009), ou seja, ele cumpre as funções de: 1) interpretar e traduzir as diversas linguagens da criança, da escola, da família; e 2) ser um espelho no qual a criança possa se reconhecer. Dessa forma, o acompanhante opera na constituição do $e \mathfrak{u}$ da criança, no surgimento do sujeito da linguagem e do discurso social. Outro aspecto importante é a posição de escuta ativa (Fráguas, 2004), na qual o acompanhante se coloca como destinatário de uma mensagem - semelhante a um escrivão que atesta um documento (González, 2002, citado por Fráguas, 2004) - reconhecendo que há uma pessoa tentando se comunicar. Associando à clínica do autismo, Fráguas pontua que o acompanhante, tendo como base suas próprias fantasias e desejos, investe na hipótese de que as várias formas de manifestação da criança, seja como um delírio, uma estereotipia ou uma ecolalia, possuem um sentido.

Isso acontece por meio do manejo da relação transferencial entre o acompanhante e a criança (Cenamo et al., 1991 citado por Fráguas \& Berlinck, 2001). É a partir da transferência e investimento de desejo que ocorre uma "antecipação do sujeito", uma aposta imaginária. Segundo os autores, apostar nas possibilidades e "antecipar o sujeito” é dar sentido às produções da criança, e para isso, é necessário supor a existência de um sujeito numa dimensão imaginária. Esse processo caracteriza-se como uma antecipação e suposição do sujeito, considerando a fragilidade subjetiva em que se encontram as crianças com embaraços no processo constitutivo.

Fráguas (2004) analisa a atribuição de sentido às "produções linguageiras" (p. 124) da criança, pontuando que é necessário considerar que se trata de uma criança que também possui sentimentos, vontades e desejos - mesmo que tais manifestações não se mostrem de um modo muito claro e acessível aos outros. Assim, o acompanhante pinça, nas falas e atitudes das crianças, sinais de seu desejo; 
age significando esse processo, para que, aos poucos, a criança possa reconhecer esse desejo como algo próprio (Fráguas, 2004). Por exemplo, se a criança expressa um eventual desejo de transitar ou permanecer em um determinado local no espaço escolar, o profissional escuta, atribui sentido, supõe e sustenta esse desejo. Essa "sustentação do desejo" é fundamental na relação estabelecida entre o acompanhante e a criança.

Seguindo essa perspectiva, uma característica de extrema relevância para o trabalho do ATE é a construção do laço social, ou "enlace". Esse termo é descrito por Albe e Magarián (1991) citado por Kupfer (2006), o qual remete à atuação do ATE no tratamento da psicose, cujo objetivo central é o estabelecimento do laço social, mas não sendo possível o laço, há um investimento em um "enlace". O enlace é compreendido como uma forma de circulação social possível.

Um elemento central que pode promover o "enlace" é o "caráter de invisibilidade" (Montellano et al., 2009) do acompanhante. Isso significa dizer que é caracterizado como um "remeter ao outro" aquilo que lhe compete: incentivar a professora a se envolver na crise ou assumir o seu lugar, já que se apresenta como a figura que conhece e decide situações no contexto da sala de aula; convocar a criança para conversas que a incluam; remeter ao porteiro, por exemplo, o cuidado que lhe cabe com a porta, entre outros aspectos. Diante disso, assumir o lugar de invisível é promover a aproximação da criança com outros atores educacionais presentes no contexto escolar, criando situações nas quais outros atores sociais se relacionem com a criança e, ao mesmo tempo, implicar a criança no seu processo de escolarização. A partir disso, as ações do acompanhante são transformadas em "pequenos nadas", pois intervenções diretas vão se transformando em indiretas. Isso acontece quando o profissional começa a se distanciar da cena para estimular e encorajar a criança a experimentar sozinha a situação (Montellano et al., 2009).

Além do que foi discutido, o acompanhante auxilia o professor a compreender a singularidade da criança (Assali et al., 1999) quando ele precisa sustentar funções mais subjetivas e simbólicas na relação com o aluno para além da função pedagógica (Kupfer \& Petri, 2000). O acompanhante contribui também para a desconstrução de crenças relacionadas à criança, possibilitando aos professores perceberem avanços para além daqueles vinculados aos processos pedagógicos ou de aprendizagem.

A repercussão do ATE, para muitos autores, tais como Kupfer (1997), Assali et al. (1999), Fráguas e Berlinck (2001) e Barros e Brandão (2011), vai além do trabalho de promoção da inclusão no contexto escolar. A sua atuação também tem claras influências sobre a vida do sujeito em todos os âmbitos da sua experiência, inclusive fora dos muros da escola. A partir de um trabalho coerente e reflexivo, 
é possível que a pessoa se torne capaz de expressar-se como sujeito e agente no curso das suas interações sociais.

\section{Autismo: considerações psicanalíticas}

Nas crianças autistas, é comum percebermos aspectos como o isolamento extremo com atitudes de indiferença em relação às pessoas e aos objetos, ritualizações, estereotipias gestuais, distúrbios de linguagem e incapacidade de utilizar pronomes (Kanner, 1943 citado por Sibemberg, 1998). De acordo com o autor, entre os sintomas mais característicos do autismo, está a dificuldade na interação social, na linguagem e nas brincadeiras simbólicas e imaginativas. É comum observar também a ecolalia, ou seja, a repetição da fala dos outros, não havendo expressão de algo próprio; não há espontaneidade ou tonalidade na fala (Fráguas, 2004). Existe, portanto, uma inserção insuficiente na linguagem socialmente compartilhada, gerando problemas na comunicação e na criação de laços sociais.

Para a psicanálise, a linguagem representa o eixo central da constituição do sujeito psíquico, o "universo da criança se organiza em torno de significações produzidas pela linguagem" (Sibemberg, 1998, p. 64). É na relação com o Outro que o sujeito pode se apropriar da linguagem, se organizar e construir um saber sobre si e sobre o mundo. A pessoa que cumpre a função materna é, para o bebê, o primeiro Outro, aquele que com o olhar, o toque e a palavra, introduz o indivíduo no circuito do desejo. Essa pessoa, geralmente a mãe, age conferindo ao seu corpo os significados que ela "atribui ao mundo das coisas e das relações intersubjetivas” (p. 65).

A criança constrói seus referentes imaginários e simbólicos pela linguagem, na relação com o outro (Sibemberg, 1998). De acordo com Laznik (2004), no autismo acontece uma falha na construção dos referentes imaginários e simbólicos. Para Sibemberg (1998), nas crianças autistas a presença do outro não gera interesse, não se percebe nenhuma significação desejante, e "a palavra não encontra ancoradouro significante” (p. 65). Em decorrência disso, há uma produção de sintomas no corpo dessas crianças, como estereotipias gestuais, movimentos repetitivos e rituais (Sibemberg, 1998). Laznik (2004) observa ainda que nessas crianças acontece a inversão pronominal eu/tu, o que para a psicanálise representa uma impossibilidade de

524 Estilos clin., São Paulo, v. 20, n. 3,set./dez. 2015, 520-534. 
aceder à constituição imaginária do eu, caracterizando uma ausência de sujeito desejante (Sibemberg, 1998).

A direção da cura do autismo, para a psicanálise, enfatiza a constituição de um sujeito psíquico, colocando a aprendizagem como consequência da sua inclusão no campo significante (Sibemberg, 1998). Assim, é necessário encontrar uma forma de pensar e tratar o autismo por meio da observação da singularidade de cada criança, considerando que existem "autismos" e não "autismo" (Sibemberg, 1998).

A partir disso, no Acompanhamento Terapêutico Escolar (ATE) com crianças autistas, é preciso considerar o fato de que a criança se encontra em processo de constituição e desenvolvimento, logo, as intervenções devem promover o desenvolvimento e a constituição subjetiva, ou resgatar esse processo quando acontecer uma "falha" ou "quebra" no processo simbólico (Parra, 2009). Considerando os efeitos terapêuticos promovidos a partir de estratégias e intervenções inclusivas, construídas no contexto educacional, o presente estudo teve por objetivo relatar uma experiência de ATE com uma criança autista, refletindo sobre alguns aspectos relacionados à emergência do sujeito.

\section{Caminhos metodológicos trilhados}

O acompanhamento foi realizado pela pesquisadora e primeira autora deste artigo com uma criança autista, dos seis aos nove anos, em uma escola privada da cidade de Salvador, Bahia. Os dados foram coletados a partir do diário de campo da acompanhante, no qual eram registrados os acontecimentos relativos ao cotidiano escolar, à relação construída entre a criança e a acompanhante, às interações entre a criança e seus pares, professores, coordenadores e funcionários da escola, além de acontecimentos durante o próprio processo do ATE. Os registros aconteciam livremente e de acordo com as observações da acompanhante a partir da sua atuação. Os aspectos referentes às interações e à emergência do sujeito foram selecionados para uma posterior realização da análise do caso, adotando-se uma perspectiva psicanalítica.

É importante destacar que foi solicitada à instituição a assinatura do Termo de Autorização Institucional e, aos pais, o Termo de Consentimento Livre e Esclarecido, para utilização dos dados para fins de pesquisa. Desse modo, foram tomados os cuidados éticos para 
preservar a integridade humana, garantir a participação voluntária e assegurar a confidencialidade das informações utilizadas.

\section{A experiência de acompanhamento terapêutico escolar com Tiago: a emergência do sujeito}

O ATE, como está sendo caracterizado neste artigo, refere-se a uma atuação específica desenvolvida no ambiente escolar. Isso significa que o relato de experiência englobará aspectos relacionados a esse contexto, como situações e conflitos vivenciados pelos atores vinculados à escola. Será dada atenção aos aspectos que concernem especificamente a esse ambiente. Considera-se, portanto, que a escola pode se configurar como um espaço potencialmente terapêutico para crianças com autismo. Assim, foram analisadas as relações construídas na escola, considerando a presença do acompanhante. Será objeto de nossa análise aquilo que acontece no tecido das relações sociais, no "entre" a criança e os outros atores escolares.

Diante disso, o relato de experiência não abrange aprofundamentos acerca das questões familiares ou sobre os atendimentos com profissionais especializados, realizados com a criança. Ela será chamada de Tiago, nome fictício utilizado para preservar sua identificação. Ele tinha seis anos quando foi iniciado o ATE. Não foi sua primeira experiência com uma acompanhante, pois no ano anterior ele fora acompanhado por um estagiário de Psicologia. Quando o trabalho de acompanhamento teve início, Tiago estava no primeiro ano do ensino fundamental I, utilizava poucas palavras (sem muita intenção comunicativa), não estabelecia contato visual nem se relacionava diretamente com os outros. Ele foi caracterizado por uma das supervisoras do estágio, naquele momento, como "uma conchinha fechada".

Tiago é o terceiro filho de uma família de três irmãos. Ele recebia atendimento de outros profissionais - psicóloga, psicopedagoga, fonoaudióloga etc. Inicialmente, Tiago não possuía um diagnóstico conclusivo de autismo, porém a escola observava algumas características peculiares, como dificuldade na comunicação e na interação social. Tiago recebeu o diagnóstico posteriormente, quando o ATE já havia iniciado, e passou a ser atendido por outros profissionais, com o objetivo de agregar diversas intervenções.

Estilos clin., São Paulo, v. 20, n. 3,set./dez. 2015, 520-534. 
Vale lembrar que a escola na qual Tiago estudava se caracteriza como construtivista, com uma proposta educativa menos conteudista, que trabalhava com a ênfase na relação entre as pessoas, a partir da interação social. A escola possuía um serviço de psicologia escolar, que realizava formação continuada de professores e supervisionava o estágio de estudantes de psicologia. Nesse serviço estavam inseridos os estagiários que atuavam com crianças com necessidades educativas especiais. Nessa escola não se utilizava o termo "acompanhamento terapêutico escolar" para descrever a prática do acompanhante. O termo é assim descrito nesse estudo na tentativa de afirmar a posição terapêutica da atuação do profissional no contexto escolar. Nessa perspectiva, a atuação é "terapêutica", por meio do aparato e representações das relações que acontecem no ambiente "escolar".

O grupo de crianças da sala de Tiago passou por várias mudanças: no início, a maior parte dos alunos era do sexo masculino. A maioria deles já conhecia Tiago, e observava de longe a sua forma de transitar no espaço escolar. No primeiro momento, os colegas não dirigiam tanto a atenção para ele, não o percebiam como aluno pertencente ao grupo; Tiago ocupava uma posição marginal em relação aos seus pares. No entanto, alguns alunos iniciaram timidamente algum movimento para entender o que acontecia com ele. Eles tinham alguma curiosidade, e buscavam explicações. Outros colegas recorriam às falas compartilhadas entre os adultos: "ele é doentinho", "ele é retardado" ou "ele é como bebê".

O ATE realizado com Tiago revelou que, para fazer intercâmbios com o meio, na tentativa de fazer laços sociais e se beneficiar dos processos de aprendizagem, Tiago precisava "ser" sujeito, precisava que sua estruturação psíquica fosse retomada. Ele não estabelecia contato direto com as pessoas, falava frases que provavelmente escutava em outros contextos, tais como: "loja de piscina", "loja de gasolina", "Madagascar" e "Jimmy Neutron"; ou, "Eu só estava brincando, você sabia, vou tirar de todos vocês". Tiago repetia a última frase diversas vezes: não demonstrava uma intenção de comunicação. Além disso, não tinha reconhecimento corporal, da rotina escolar, dos seus colegas, professora, dos próprios materiais; tudo lhe parecia indiferente.

A direção do trabalho de acompanhamento, inicialmente, foi tomar suas falas - aparentemente soltas - como mensagens, e convocá-lo a expressar o que desejava. A proposta era que Tiago pudesse sair da fase do apontar ou utilizar o corpo do outro como ferramenta, e passasse a falar efetivamente, assumindo uma posição de fala. O investimento na fala se deu de várias formas. Quando ele falava "isso não é um menino feliz", "eu não aguento mais isso", "vai cuidar da sua vida", ou "você que tem que me ajudar", a acompanhante entendia essas frases como mensagens, como tentativa de comunicar algo; ou melhor, antecipava que aquela frase se transformaria em um pedido ou reclamação. A acompanhante 
perguntava, devolvia a frase para ele, esboçando o início de um diálogo. Nesse sentido, a acompanhante se posicionava como destinatário de uma mensagem, compreendendo que as mais variadas formas de manifestação da criança possuem um sentido (Fráguas, 2004).

Assumindo uma função de presença ativa na escola, ocupando o lugar de intérprete e tradutor das diversas linguagens (da criança, da escola, da família), oferecendo-se como "espelho" (Montellano et al., 2009) e se posicionando como receptor das mensagens, a acompanhante percebia que Tiago começava a utilizar mais frases que pareciam expressar algo que ele desejava comunicar. Ele utilizava, como empréstimo, as falas da acompanhante e de outras pessoas, diante da impossibilidade de construir frases próprias. Um exemplo disso pôde ser observado quando ele era chamado para voltar à sala após o recreio; ele aceitava, mas começava a falar "eu não mereço, eu não mereço!", e quando a interação com os colegas se tornava difícil, ele passava a utilizar "agora eu não posso, Lary!” (um personagem de desenho animado).

Com algumas frases consideradas verdadeiras convocações, como "O que você quer, Tiago?”, ele começou a utilizar "eu quero" e "quero não". Em muitos momentos, falava em terceira pessoa: "ele quer" ou "quer". Conseguia expressar vontade de ir ao banheiro, beber água, lanchar, receber carinho, até chegar ao pedido para sair da sala. A permanência em sala era muito difícil para ele naquele momento, então ele sempre escapava, saía correndo da sala. Havia a compreensão, na escola, de que era complicado mantê-lo ali, sentado, realizando alguma atividade, mas tínhamos que estabelecer bordas e enlaçá-lo em regras e acordos sociais. A acompanhante e a professora começaram a combinar algumas saídas, mas ele tinha que pedir à professora para sair. Havia, nesse movimento, a antecipação de um sujeito de desejo, um sujeito falante, a aposta imaginária do adulto nas possibilidades daquela criança (Fráguas \& Berlinck, 2001).

A tentativa do ATE de Tiago foi pinçar, nas suas falas e atitudes, sinais de uma manifestação de algo do seu desejo, para significar o processo e, posteriormente, reconhecer esse desejo como seu, como próprio (Fráguas, 2004). Diante disso, é fundamental retomar a importância da sustentação do "desejo" da criança pela circulação do espaço físico da escola e pelo estabelecimento de relações que vão sendo construídas. Esse aspecto mostra sua relevância, por representar uma antecipação do desejo, o qual é significado pelo acompanhante, que o sustenta para a própria criança e para a escola, a despeito das demandas e questionamentos dos demais atores escolares. Tiago frequentava bastante a biblioteca, no recreio e nas saídas da sala, o que se tornou o início para a antecipação de um desejo e de sua 
sustentação. A acompanhante iniciou algumas intervenções a partir de uma antecipação, perguntado se ele queria ir para a biblioteca, para o parque, para a sala, dando um sentido para seu movimento. $\mathrm{Na}$ medida em que Tiago começou a falar que queria ir para a biblioteca, o impasse se direcionava para a escola, diante das regras e dos horários previamente estipulados pela instituição. Nesse momento, foi fundamental sustentar seu desejo, "garantir" que poderia ser efetivado, a partir de um trabalho conjunto à escola, para que Tiago pudesse tomá-lo como seu.

Isso foi possível por meio da relação transferencial que fora estabelecida entre a acompanhante e Tiago, a qual não era interpretada, e sim manejada para a realização do acompanhamento (Cenamo et al., 1991 citado por Fráguas \& Berlinck, 2001). No ATE, o processo transferencial precisa ser considerado, pois também se ocupa um lugar de Outro. De acordo com Levin (2010), a transferência atualiza, produz efeitos que vão operar retroativamente, permitindo sua elaboração. No trabalho clínico com crianças, é necessário haver a disponibilidade corporal, por parte do profissional, para incluir o próprio corpo na cena, sendo o que favorece o desdobramento espontâneo das fantasias que se corporificam (Levin, 2010).

A disponibilidade corporal é fundamental para o ATE, pois o profissional precisa estar presente e disponível corporalmente nas cenas cotidianas do contexto escolar. $\mathrm{O}$ acompanhante deve estar disponível para servir de instrumento e de espaço para os desdobramentos das fantasias. Tiago utilizava, inicialmente, o corpo da acompanhante como ferramenta, depois como extensão do dele ou como uma mistura entre ambos (era difícil para ele, por exemplo, perceber se as sensações que sentia ocorriam nele ou na acompanhante). Após um período, ele passou a abraçar a acompanhante com força, mexer no seu cabelo e sentir curiosidade para ver sua barriga. Dessa forma, as intervenções aconteciam por meio do corpo e da relação transferencial.

Sobre o corpo de Tiago, era perceptível sua dificuldade para reconhecer a si mesmo; suas sensações. Ele parecia não se reconhecer, sentia-se confuso em relação às partes do corpo, não mostrava incômodo quando se machucava, não expressava sinais de dor. Esses aspectos revelam que Tiago tinha questões no esquema corporal, pela fragilidade na sua imagem corporal. Estes são elementos importantes e conceitos fundamentais que fazem referência à construção da subjetividade e estruturação psíquica. Segundo Yañez (1996/2008), 
a imagem corporal fala da constituição do sujeito, sendo singular e inconsciente; o esquema é pré-consciente. Levin (2000) explica que o esquema é uma representação do corpo, sendo a imagem constituinte do sujeito desejante, que vai se constituindo no devir histórico da experiência subjetiva. O esquema corporal implica uma representação, já que a criança pode falar do corpo, das suas partes, funções, relações espaciais e da dimensão temporal do corpo (Yañez, 1996/2008). Diante disso, Tiago não tinha como representar e/ou reconhecer seu corpo antes da emergência do sujeito; antes de construir uma imagem corporal possível. É necessário, portanto, constituir a imagem do corpo para haver o esquema corporal.

Durante o ATE com Tiago, foi observado que era possível intervir com o brincar espontâneo, aproveitando suas iniciativas e os espaços da escola. Então, no banheiro, brincavam com o espelho: a acompanhante perguntava para ele quem estava aparecendo ali. Inicialmente, ele respondia "é o menino", até que passou a falar "é Tiago" e a demonstrar satisfação com essa brincadeira e com o seu reflexo. Na sala, na biblioteca, no parque e em outros espaços, a acompanhante brincava de pegar nas partes do corpo e do rosto, e faziam caretas. Tiago ficava confuso com o que era do outro e o que era dele, e aos poucos foram elaborando conjuntamente a diferenciação dos corpos, dos rostos e das sensações. Tiago passou a reconhecer e brincar com o "soltar pum"; começou a mostrar quando se machucava, falando: "machucou meu joelho", "meu braço".

As brincadeiras de reconhecimento do corpo e da imagem podem ser caracterizadas como o brincar constitutivo, visto que apontam para o processo de constituição do sujeito. Tiago, após um ano de acompanhamento, começou a falar "quer morder o bracinho?" e colocava o braço na boca do adulto (fazia isso com a acompanhante e com a professora em alguns momentos) para que fingissem estar se deliciando com a mordida; também esperava a finalização da brincadeira, que terminava com a fala "hum, que bracinho mais gostoso!", a qual era induzida por ele, mas tinham que acompanhá-lo. Provavelmente, Tiago estava reatualizando, na transferência, algo que fazia com outras pessoas; mas é importante observar como esse brincar parece retomar o terceiro tempo do circuito pulsional, como analisa Laznik (2004). A autora, seguindo o trajeto pulsional de Freud, situa o processo de alienação nesse terceiro tempo, e afirma que a criança se faz objeto de um novo sujeito, o que revela um assujeitamento a um outro, o qual sustentará o lugar de um grande Outro primordial, que fala no seu lugar e fornece os significantes que serão utilizados por ela posteriormente.

Outro exemplo de brincar constitutivo refere-se aos momentos do esconder-se. Tiago iniciou a brincadeira de esconder o rosto na camisa com um colega. Depois, passou a brincar de se esconder da acompanhante na mesa. Isso mostra a brincadeira de presença e ausência, o "Fort-Da". O jogo do "Fort-Da" 
mostra que a possibilidade para a emergência de um sujeito não acontece nem pela simples continuidade nem pela descontinuidade em si, mas pela possibilidade de articular uma série presença-ausência (Jerusalinsky, 2011a). A autora (2011b) situa a brincadeira do "cadê-achou" como um jogo precursor do "Fort-Da" (um jogo de construção de um litoral), a qual pode ser associada à primeira brincadeira com Tiago, quando escondia e mostrava o rosto; ela também pontua que a criança, ao brincar de se esconder, em um tempo posterior ao "Fort-Da", brinca de produzir falta no Outro. Essa brincadeira foi observada com Tiago, quando ele se escondia da acompanhante atrás da mesa. Desse modo, parece haver uma retomada da terceira operação constituinte do sujeito, a alternância de presença e ausência. Jerusalinsky (2002) enfatiza que é a alternância simbólica que permitirá a inscrição pulsional do bebê, e um Outro primordial, somente presença ou ausência, não permite tal inscrição. Essa operação introduz um ritmo dos cuidados do bebê. Tiago não era mais um bebê, por isso parece haver uma retomada de algo que foi interrompido ou se manteve embaraçado.

Neste artigo não foram analisadas as questões e a relação de Tiago com sua família, nem os processos de tratamento com os outros profissionais que o atendiam: enfatizaram-se o ATE e seus efeitos. No entanto, acredita-se que Tiago vivenciava, concomitante ao acompanhamento, outras relações e intervenções, as quais também produziram repercussões significativas no seu desenvolvimento.

\section{Considerações finais}

Diante da discussão proposta pordeste artigo, observa-se que a experiência do ATE no processo inclusivo de Tiago demonstrou efeitos significativos para a utilização da fala como recurso comunicativo, para as interações sociais e para a emergência do sujeito. Sendo assim, esse acompanhamento tem se mostrado uma modalidade de intervenção eficiente nas práticas inclusivas, visto que trabalha a partir das relações construídas no contexto escolar, criando e utilizando mecanismos para que a criança possa circular no espaço educacional, beneficiando-se daquilo que a escola pode oferecer. Além disso, o ATE pode promover efeitos terapêuticos relevantes, nos quais há a possibilidade da construção do laço social (ou "enlace") e a retomada 
da constituição subjetiva. O ATE representa, sobretudo para as crianças com autismo, uma possibilidade de estar no ambiente escolar, de circular socialmente, de ser visto, de expor suas estranhezas, de se relacionar, de ser escutado, de ser sujeito falante, de ser sujeito de desejo. Considera-se, desse modo, relevantes os efeitos terapêuticos da inclusão para crianças com questões subjetivas e o ATE como uma possibilidade de atuação que se direciona por essa perspectiva.

THERAPEUTIC ACCOMPANIMENT AT SCHOOL AND AUTISM: PATHS TO THE EMERGENCY OF SUBJECT

\begin{abstract}
This paper aims to report a therapeutic monitoring experience at school with an autistic child, carried out for three and a half years in a private school in Salvador. Data were recorded in a diary and analyzed from the psychoanalytic approach. There were significant developments about the emergence of the subject, such as changes in speech, recognition of himself, of his body and at symbolic playing. This practice shows up as an important resource for the inclusion and development of autistic children.
\end{abstract}

Index terms: therapeutic monitoring; school inclusion; autism.

ACOMPAÑ AMIENTO TERAPÉUTICO EN LA ESCUELA Y AUTISMO: CAMINOS A LA EMERGENCLA DEL SUJETO

\title{
RESUMEN
}

Este texto tiene el propósito de informar sobre una experiencia de acompañamiento terapéutico en una escuela con un niño autista, realizada durante tres años y medio en un colegio privado de Salvador, Brasil. Se registraron los datos en un diario y se los analizaron desde el enfoque psicoanalítico. Se produjeron avances significativos relacionados con la emergencia del sujeto, tales como, cambios en el habla, reconocimiento de sí mismo, del cuerpo y del juego simbólico. La práctica muestra como un recurso importante para la inclusión y el desarrollo de niños autistas.

Palabras clave: acompañamiento terapéutico; inclusión escolar; autismo.

\section{REFERÊNCIAS}

Assali, A. M., Rizzo, C., Abbamonte, R. M., \& Amâncio, V. (1999). O acompanhamento terapêutico na inclusão de crianças com distúrbios globais do desenvolvimento. In Anais do I Colóquio do Lugar de Vidal LEPSI: a psicanálise e os impasses da educação (pp. 114-121). São Paulo, SP: Lugar de Vida.

Barros, J. F., \& Brandão, D. B. S. R. (2011). Acompanhamento terapêutico: (re) pensando a inclusão escolar. In X Congresso Nacional de Psicologia Escolar $e$ Educacional. Maringá, PR. Recuperado de http://www.abrapee.psc.br/xconpe/ trabalhos/1/39.pdf

Declaração de Salamanca (1994). In Conferência Mundial sobre Necessidades Educativas Especiais. Salamanca/Espanha: UNESCO. Recuperado de http://

532 Estilos clin., São Paulo, v. 20, n. 3,set./dez. 2015, 520-534. 
portal.mec.gov.br/seesp/arquivos/pdf/ salamanca.pdf

Fráguas, V. (2004). Acompanhamento terapêutico com crianças: sobre a função terapêutica da construçáo do laço social. Revista Pediatria Moderna/Psicologia em Pediatria, 40(3), 120-124. Recuperado de http://www.moreirajr.com.br/revistas. asp?id_materia $=2621 \&$ fase $=$ imprime

Fráguas, V., \& Berlinck, M. T. (2001). Entre o pedagógico e o terapêutico: algumas questôes sobre o acompanhamento terapêutico dentro da escola. Estilos da Clínica, 6(11), 7-16. DOI: http://dx.doi.org/10.11606/ issn.1981-1624.v6i11p7-16

Jerusalinsky, J. (2002). É possível prevenir ou só resta remediar? Precocidade e prevenção na intervenção com bebês. In J. Jerusalinsky, Enquanto o futuro não vem: a psicanálise na clinica com bebês (pp. 224257). Salvador, BA: Ágalma.

Jerusalinsky, J. (2011a). Jogos de litoral na direção do tratamento de crianças em estados autísticos. Revista Associação Psicanalítica de Curitiba, (22), 77-89.

Jerusalinsky, J. (2011b). Jogos constituintes do sujeito: o brincar no laço mãe-bebê como inscrição de um litoral. In J. Jerusalinsky, $A$ criação da criança: brincar, gozo e fala entre a mãe e o bebê (pp. 229-269). Salvador, BA: Álgama.

Kupfer, M. C. M. (1997). Educação terapêutica: o que a psicanálise pode pedir à educação. Estilos da Clínica, 2(2), 5361. DOI: http://dx.doi.org/10.11606/ issn.1981-1624.v2i2p53-61

Kupfer, M. C. M. (2006). Duas notas sobre a inclusão escolar. Escritos da criança, (6), 71-8.

Kupfer, M. C. \& Petri, R. (2000). "Por que ensinar a quem não aprende?”. Estilos da clinica, 5(9), 109-117. DOI: http:// dx.doi.org/10.11606/issn.1981-1624. v5i9p109-117

Laznik, M. C. (2004). Poderíamos pensar numa prevenção da síndrome autista? In M. C. Laznik, A voz da sereia: o autismo e os impasses na constituição do sujeito (D. B. Wanderley, trad., pp. 21-35). Salvador, BA: Ágalma.

Levin, E. (2000) O corpo e o outro. In E. Levin, A clinica psicomotora: o corpo na linguagem (J. Jerusalinsky, trad.). Petrópolis, RJ: Vozes.

Levin, E. (2010) A Transferência na terapia psicomotora. In A. Jerusalinsky, Psicanálise $e$ desenvolvimento infantil: um enfoque transdisciplinar (5a ed., pp. 201-217). Porto Alegre, RS: Artes e ofícios.

Montellano, C. P., Nero, C. T. D., Sereno, D., Garfunkel, J. L., Vicentin, M. C. G., Almeida, M. N. C., \& Navarro, N. C. (2009). Educação inclusiva: construindo modos de ação na interface saúde-educação. In A. A. Anache \& I. R. Silva (Orgs.), Educação inclusiva: experiências profissionais em psicologia (pp. 53-68). Brasília, DF: Conselho Federal de Psicologia.

Parra, L. S. (2009). Atando laços e desatando nós: reflexóes sobre a função do Acompanhamento Terapêutico na Inclusão de crianças autistas. (Dissertação de Mestrado). Instituto de Psicologia, Universidade de Brasília, Brasília, DF. Recuperado de http://bdtd.bce.unb.br/ tedesimplificado/tde_busca/arquivo. php? codArquivo $=5301$

Pegorelli, A. L. C. B. (2011). Um acompanhamento terapêutico na escola: seus alcances e possíveis entraves. In VIII Colóquio Internacional do LEPSI/ III Congresso da $R u e p s y-O$ declinio dos saberes e o mercado do gozo: a psicanálise na educação. São Paulo, SP. Recuperado de http://www. proceedings.scielo.br/scielo.php?pid=MSC0000000032010000100006\&script $=s-$ ci_arttext

Pitiá, A. C. A., \& Furegato, A. R. F. (2009). O acompanhamento terapêutico (AT): dispositivo de atenção psicossocial em saúde mental. Interface: Comunicação, Saúde, Educação, 13(30), 67-77. DOI: http://dx.doi.org/10.1590/ S1414-32832009000300007 
Prieto, R. G. (2005). Inclusão escolar: algumas consideraçóes sobre o conceito e suas implicaçóes. In A. M. Machado, A. J. Veiga Neto, M. M. B. J. Neves, M. V. O. Silva, R. G. Prieto, W. Ranña, \& E. Abenhaim (Orgs.), Educação inclusiva: direitos humanos na escola (pp. 99-106). São Paulo: Casa do Psicólogo.

Sibemberg, N. (1998). Autismo e linguagem. Escritos da criança, (5), 60-72.

Yañez, Z. (2008). Psicomotricidade e seus conceitos fundamentais: esquema e imagem corporal. Escritos da criança, (4), 32-41. (Trabalho original publicado em 1996)

veronica_gomes_nascimento@hotmail.com Rua Alegria do Castro Neves, 51/08 40255-240 - Salvador - BA - Brasil.

asouzap@yahoo.com.br

Rua Franknalva Souza, 62 41310-340 - Salvador - BA - Brasil.

dazzani@superig.com.br

Rua Rodrigo Argolo, 251/501 41940-220 - Salvador - BA - Brasil. 